\title{
Physical Activity, Yoga and their Psychological Effects
}

Karel Nespor, M.D., Ph.D.

\section{Introduction}

In 2006 I participated in a seminar in Slovenia led by a well-known Indian master ${ }^{3}$. Among others, he demonstrated the exercise which slows down the aging of the brain. After I returned home, I searched medical literature, and to my surprise found out that physical activity is beneficial for the brain in more than one way (Nespor a Csémy, 2006). Ever since, many new and practically important findings appeared.

\section{Psychological effects of physical activity}

\section{Cognitive functions such as memory, attention and concentration}

The positive effect of physical activity on cognitive functions has been confirmed by many authors. It includes all age categories - this effect was observed in adolescents (Subramanian et al., 2015) as well as in people over 70 (Bouaziz et al., 2017). One of the possible mechanisms is that physical activity stimulates the secretion of BDNF (brain-derived neurotrophic factor, Heijnen et al., 2016). BDNF prolongs the survival of existing neurons and promotes the growth of new nerve cells and synapses.

\section{Amelioration of depressive symptomatology}

The positive effect of physical activity in depression takes place even in the more serious forms of depression (Bewernick et al., 2017). Sun et al., (2016) applied walking in combination with a relaxation technique in the patients with breast cancer. It was found that physical activity ameliorated depression and decreased the risk of suicidal behaviour. Coping with depression prevents the impairment of cognitive functions later in life (Mathersul and Rosenbaum, 2016) and premature death. Siqueira et al. (2016) came to similar conclusions and these authors found that physical activity enhanced the effect of antidepressants.

\section{Reducing anxiety}

An extensive international study by Stubbs et al. (2017) found that an adequate physical activity was related to the lower mortality rate. According to these authors, physical activity improved social interaction.

\section{Physical activity and anger}

Even moderate physical activity, such as walking, influences emotional state (Sakuragi and Sugiyama, 2006, Yuenyongchaiwat, 2016). Anger and excessive physical activity increase the risk of the heart attack (Smyth et el., 2016) and it can be presumed that the combination of these two factors will make the risk even higher. The study by Pels et al., (2016) was related to anger. These authors found that non-aggressive physical activity, it was rowing in their experiment, reduced anger, but practicing martial arts had no such effect.

\footnotetext{
${ }^{3}$ Paramahansa Niranjanananda Saraswati: Workshop Yoga - Awakening of Inner Potential, Ankaran, Sloveni4a 25.5. - 27.5. 2006.
} 
Improved health

Physical activity is a prevention of cardiovascular diseases and other diseases affecting central nervous system.

\section{Physical activity and relaxation}

Relaxation take place spontaneously after previous physical activity and physical activity makes easier to practice a relaxation technique. Probably that is why a longer relaxation is usually used at the end yogic sessions.

\section{Physical activity and craving}

Physical activity helps to overcome craving for addictive substances and improves the quality of life of addicted people (Giménez-Meseguer et al., 2015, Tritter et al., 2015). Cravings for food can be ameliorated even by the imagination of a favorite physical activity (Knäuper et al., 2011).

\section{Healthy self-confidence}

Adequate amount of physical activity strengthens self-confidence. Among other reasons, it helps to perceive the body and its capabilities more positively (Zamani et al., 2016).

\section{Social aspects of physical activity}

Hiking or exercising in groups enable to meet new friends. However, social factors might cause also problems. We found that teenage football players consume more alcohol compared to their peers (Nespor and Csémy, 2016).

\section{Professional sports}

Professional sports often represent a risk rather than a protective factor. Competitive environment, stress and excessive efforts do nod benefit neither physical nor mental health. We met quite often patients who considered a professional sport as their main priority. They had to end their sport career suddenly because of an injury or lack of results. Their value system collapsed and they developed mental problems and addictions.

\section{Psychological effects of yoga}

Most yoga practitioners in the West practice yogic physical exercises. Some of these practices require a reasonable physical effort and there are many dynamic yogic exercises (e.g. Sun Salutation). The above mentioned positive effects of physical activities can be achieved by yoga as well.

\section{Cognitive functions}

Gothe et al. (2017) found that yogic exercises improved cognitive functions of older people. Goethe et al. (2016) presume that one of the reasons why yoga protects the cognitive functions is that it lowers stress. Butzer et al. (2016) described the positive effects of yoga on concentration and awareness of young musicians. These persons also experienced lower stage fright. The positive effect of yoga on executive functions ${ }^{4}$ was observed in adolescents who underwent a three months yoga traing (Purohit and Pradhan. 2016).

\footnotetext{
${ }^{4}$ Executive functions include attentional control, inhibitory control, working memory, cognitive flexibility, reasoning, problem solving, planning, etc.
} 


\section{Relieving depression and anxiety symptomatology}

Both physical activity and yoga ameliorate depression (Chu et al. 2017). Helgadóttir et al. (2016) found that yoga and aerobics are about equally effective on easing the symptoms of depression. Sharma et al. (2017) found that yogic breathing was useful in depressed persons who were resistant to pharmacotherapy. Morgan et al. (2016) described positive effects of yoga in generalized anxiety disorder.

\section{Relaxation}

Yoga enhances self-awareness and it makes easier to relax (Gaiswinkler and Unterrainer, 2016). Relaxation has many benefits, and even more so in combination with physical activity. Bhargav et al. (2016) found that the cognitive functions of persons with multiple sclerosis were improved by yogic relaxation. Yogic relaxation was useful in anxiety, depression (Rani et al., 2012) and menstrual irregularities (Rani et al., 2011).

\section{Pain relief}

One of the common indications of relaxation techniques is to relieve pain of various origin (Nespor, 1998) and yoga is effective in pain management as well (e.g. Kan et al., 2016, Gonçalves et al., 2017).

\section{Yoga and the prevention or treatment of addictive diseases}

- Stress contributes to the development of an addictive diseases and complicates their treatment. Addictive diseases increase the risk of stressful life events which cause even greater stress. A typical symptom of all addictive diseases is craving which is accompanied by stress. That is why stress relief improves self-control and makes coping with cravings easier.

- Yoga and meditation promote a healthier lifestyle and can be used as prevention of addictive diseases (Berent et al. 2014, Haaga et al., 2011, Penman et al., 2012).

- Yoga and meditation techniques enhance self-awareness (Lyons and Cantrell, 2016, Davis et al., 2013). Selfcontrol is closely related to self-awareness because a person can recognize craving and other risky mental states, such as exhaustion or strong emotions, at an early stage and overcome them faster.

- Yoga develops spirituality (Woodside a Culos-Reed, 2016) and spirituality is useful both in the prevention and treatment of addictions (Nespor, 2013).

- When treating addiction, yoga can be combined with other methods (Grow et al., 2014, Alfonso et al., 2011) to strengthen their effect.

- Reddy et al. (2014) found that consumption of alcohol and drugs in women with posttraumatic stress disorder has decreased after yoga practices. Some author even report to use yoga in to treat withdrawal (Zhuang et al., 2013).

- Shahab et al. (2013) found that people addicted to nicotine crave less after simple yogic breathing practices. Movement is often synchronized with breathing in yoga. Abdominal breathing is typical for relaxation and has a calming effect and is used both in yoga and qigong. When working with patients, we emphasize the importance of abdominal breathing in everyday life. It helps to calm down and overcome craving even during normal everyday activities in a discreet way. 


\section{Education}

It is possible to integrate simple yogic exercises into an educational system. Ferreira-Vorkapic et al. (2015) found that the students who practiced yoga were less tense and anxious and their self-confidence and memory had improved. Sethi et al. (2013) reported similar results.

\section{Other effects}

- In comparison with weight training, yoga made women more confident and happy with their body. They felt more secure when interacting with other people (Gammage et al., 2016).

- Donnelly et al. (2016) found that the quality of life of adults who suffered a brain injury improved after eight weeks of yoga training.

- Gaiswinkler and Unterrainer (2016) found that people who consistently practiced yoga had a better spiritual life and self-awareness and less symptoms of depression. Yoga can also be useful for older people with sleep disorders (Halpern et al., 2014).

\section{Social aspects of yoga}

Properly chosen yogic exercises are suitable even for people who are lonely, old or ill. It may enrich they social support network and resilience. Motivation for doing yoga is often related to health and most yoga practitioners live in a healthier way than the general population. It has a positive impact on group members.

\section{Psychological risks of yoga and some contraindications}

People with psychotic illnesses should not practice lengthy meditation or relaxation practices. Some people fall asleep during long relaxation techniques which is problematic in epilepsy. People with epilepsy should also avoid some yogic breathing practices. Certain yoga exercises have specific contraindications, for example the postures where the head is below the heart level are contraindicated in glaucoma. The risks related to yoga are considerably lower than in most sports. Even so caution is advisable, especially in the people over 65.

\section{Some practices similar to yoga}

- Qigong has a lot in common with yoga. It also emphasizes self-awareness and breathing is harmonised with movements. There are also many qigong relaxation and meditation techniques.

- Physiotherapeutic exercises are also practiced slowly and with awareness. Some of them originate from yoga or are similar to it, for example the Cobra position in the McKenzie exercises.

- M. Kataria created so called "Laughter Yoga". It is not a traditional yoga, but from our experience we know that laughter and humour can make a yoga class or psychotherapy more pleasant (Nespor, 2015). Besides that, laughter is a form of stress prevention and it offers many other benefits as well. Yim (2016) fond that laughter influences the biochemical changes which are typical for stress and it affects serotonin, dopamine and endorphin metabolism in the brain. Cha a Hong (2015) explains that laughter eases depressive symptomatology by affecting serotonin metabolism. It can also ameliorate pain. Dunbar et al. (2012) presume that increased secretion of endorphins secretion during laughter facilitates social bonds in everyday social life. We reviewed the benefits of laughter elsewhere (Nespor, 2016). 


\section{Conclusion}

Adequate physical activity and yoga considerably improve mental state and productivity. The positive effects of yoga on mental health are caused by many factors. Besides physical activity it is also overall and partial relaxation, mindfulness, breath regulation and spirituality. Health professionals should recommend adequate, systematic and regular physical activity and yoga to their patients whenever appropriate.

\section{Literature}

Alfonso JP, Caracuel A, Delgado-Pastor LC, Verdejo-García A. Combined goal management training and mindfulness meditation improve executive functions and decision-making performance in abstinent polysubstance abusers. Drug Alcohol Depend. 2011; 117(1):78-81.

Berent GR, Zeck JM, Leischner JA, Berent EA. Yoga as an alternative intervention for promoting a healthy lifestyle among college students. J Addict Nurs. 2014; 25(4):167-71.

Bewernick BH, Urbach AS, Bröder A et al. Walking away from depression-motor activity increases ratings of mood and incentive drive in patients with major depression. Psychiatry Res. 2017; 247:68-72.

Bhargav P, Bhargav H, Raghuram N, Garner C. Immediate effect of two yoga-based relaxation techniques on cognitive functions in patients suffering from relapsing remitting multiple sclerosis: A comparative study. Int Rev Psychiatry. 2016; 28(3):299-308.

Bouaziz W, Vogel T, Schmitt E. et al. Health benefits of aerobic training programs in adults aged 70 and over: a systematic review. Arch Gerontol Geriatr. 2017; 69:110-127.

Butzer B, Ahmed K, Khalsa SB. Yoga Enhances Positive Psychological States in Young Adult Musicians. Appl Psychophysiol Biofeedback. 2016; 41(2):191-202.

Davis JM, Mills DM, Stankevitz KA et al. Pilot randomized trial on mindfulness training for smokers in young adult binge drinkers. BMC Complement Altern Med. 2013; 13:215.

Donnelly KZ, Linnea K, Grant DA, Lichtenstein J. The feasibility and impact of a yoga pilot programme on the quality-of-life of adults with acquired brain injury. Brain Inj. 2016 Dec 12:1-7. [Epub ahead of print]

Dunbar RI, Baron R, Frangou A et al. Social laughter is correlated with an elevated pain threshold. Proc Biol Sci. 2012; 279(1731):1161-7.

Ferreira-Vorkapic C, Feitoza JM, Marchioro M et al. Are There Benefits from Teaching Yoga at Schools? A Systematic Review of Randomized Control Trials of Yoga-Based Interventions. Evid Based Complement Alternat Med. 2015; 2015:345835.

Gaiswinkler L, Unterrainer HF. The relationship between yoga involvement, mindfulness and psychological well-being. Complement Ther Med. 2016; 26:123-7.

Gammage KL, Drouin B, Lamarche L. Comparing a Yoga Class with a Resistance Exercise Class: Effects on Body Satisfaction and Social Physique Anxiety in University Women. J Phys Act Health. 2016; 13(11):1202-1209.

Giménez-Meseguer J, Tortosa-Martínez J, de los Remedios Fernández-Valenciano M. Benefits of Exercise for the Quality of Life of Drug-Dependent Patients. J Psychoactive Drugs. 2015; 47(5):409-16. 
Gonçalves AV, Barros NF, Bahamondes L. The Practice of Hatha Yoga for the Treatment of Pain Associated with Endometriosis. J Altern Complement Med. 2017; 23(1):45-52.

Gothe NP, Keswani RK, McAuley E. Yoga practice improves executive function by attenuating stress levels. Biol Psychol. 2016; 121(Pt A):109-116.

Gothe NP, Kramer AF, McAuley E. Hatha Yoga Practice Improves Attention and Processing Speed in Older Adults: Results from an 8-Week Randomized Control Trial. J Altern Complement Med. 2017; 3; 23(1):35-40.

Grow JC, Collins SE, Harrop EN, Marlatt GA. Enactment of home practice following mindfulness-based relapse prevention and its association with substance-use outcomes. Addict Behav. 2014; 40C:16-20.

Haaga DA, Grosswald S, Gaylord-King C et al. Effects of the Transcendental Meditation Program on Substance Use among University Students. Cardiol Res Pract. 2011; 2011:537101.

Halpern J, Cohen M, Kennedy G et al. Yoga for improving sleep quality and quality of life for older adults. Altern Ther Health Med. 2014; 20(3):37-46.

Heijnen S, Hommel B, Kibele A, Colzato LS. Neuromodulation of Aerobic Exercise-A Review. Front Psychol. 2016; 6:1890.

Helgadóttir B, Hallgren M, Ekblom Ö, Forsell Y. Training fast or slow? Exercise for depression: A randomized controlled trial. Prev Med. 2016; 91:123-131.

Cha MY, Hong HS. Effect and Path Analysis of Laughter Therapy on Serotonin, Depression and Quality of Life in Middle-aged Women. J Korean Acad Nurs. 2015; 45(2):221-30.

Chu IH, Wu WL, Lin IM et al. Effects of Yoga on Heart Rate Variability and Depressive Symptoms in Women: A Randomized Controlled Trial. J Altern Complement Med. 2017 Jan 4. [Epub ahead of print].

Kan L, Zhang J, Yang Y, Wang P. The Effects of Yoga on Pain, Mobility, and Quality of Life in Patients with Knee Osteoarthritis: A Systematic Review. Evid Based Complement Alternat Med. 2016; 2016:6016532.

Knäuper B, Pillay R, Lacaille J et al. Replacing craving imagery with alternative pleasant imagery reduces craving intensity. Appetite. 2011; 57(1):173-8.

Lyons T, Cantrell WD. Prison Meditation Movements and Mass Incarceration. Int J Offender Ther Comp Criminol. 2016; 60(12):1363-75.

Mathersul DC, Rosenbaum S. The Roles of Exercise and Yoga in Ameliorating Depression as a Risk Factor for Cognitive Decline. Evid Based Complement Alternat Med. 2016; 2016:4612953.

McNamara C, Johnson M, Read L et al. Yoga Therapy in Children with Cystic Fibrosis Decreases Immediate Anxiety and Joint Pain. Evid Based Complement Alternat Med. 2016; 2016:9429504.

Morgan JR, Sullivan M, Masuda A et al. A Case Series on the Effects of Kripalu Yoga for Generalized Anxiety Disorder. Int J Yoga Therap. 2016; 26(1):9-19.

Nespor K, Csémy L. Psychotropní účinky tělesné aktivity. Praktický lékař 2006, 86(11):672.

Nespor K. Smích a medicína. Praktický lékař 2015; 95(4):187-189. 
Nespor, K.: Uvolněně a s přehledem. Relaxace a meditace pro moderního člověka. Praha: Grada 1998; 96.

Nespor K. Spiritualita v psychiatrii. Psychiatrie pro praxi 2013; 14(2):51.

Paramahansa Niranjanananda Saraswati: Workshop Yoga - Awakening of Inner Potential, Ankaran, Slovenina 25.5. - 27.5. 2006.

Pels F, Kleinert J. Does Exercise Reduce Aggressive Feelings? An Experiment Examining the Influence of Movement Type and Social Task Conditions on Testiness and Anger Reduction. Percept Mot Skills. 2016; 122(3):971-87.

Penman S, Cohen M, Stevens P, Jackson S. Yoga in Australia: Results of a national survey. Int J Yoga. 2012; 5(2):92-101.

Purohit SP, Pradhan B. Effect of yoga program on executive functions of adolescents dwelling in an orphan home: A randomized controlled study. J Tradit Complement Med. 2016; 7(1):99-105.

Rani K, Tiwari S, Singh U et al. Impact of Yoga Nidra on psychological general wellbeing in patients with menstrual irregularities: A randomized controlled trial. Int J Yoga. 2011; 4(1):20-5.

Rani K, Tiwari S, Singh U et al.. Yoga Nidra as a complementary treatment of anxiety and depressive symptoms in patients with menstrual disorder. Int J Yoga. 2012; 5(1):52-6.

Reddy S, Dick AM, Gerber MR, Mitchell K. The effect of a yoga intervention on alcohol and drug abuse risk in veteran and civilian women with posttraumatic stress disorder. J Altern Complement Med. 2014; 20(10):750-6.

Sakuragi S, Sugiyama Y. Effects of daily walking on subjective symptoms, mood and autonomic nervous function. J Physiol Anthropol. 2006; 25(4):281-9.

Sethi JK, Nagendra HR, Sham Ganpat T. Yoga improves attention and self-esteem in underprivileged girl student. J Educ Health Promot. 2013; 2:55.

Shahab L, Sarkar BK, West R. The acute effects of yogic breathing exercises on craving and withdrawal symptoms in abstaining smokers. Psychopharmacology (Berl). 2013; 225(4):875-82.

Sharma A, Barrett MS, Cucchiara AJ et al. A Breathing-Based Meditation Intervention for Patients With Major Depressive Disorder Following Inadequate Response to Antidepressants: A Randomized Pilot Study. J Clin Psychiatry. 2017; 78(1):e59-e63.

Schuch F, Vancampfort D, Firth J. et al. Physical activity and sedentary behavior in people with major depressive disorder: A systematic review and meta-analysis. J Affect Disord. 2016; 210:139-150

Siqueira CC, Valiengo LL, Carvalho AF et al. Antidepressant Efficacy of Adjunctive Aerobic Activity and Associated Biomarkers in Major Depression: A 4-Week, Randomized, Single-Blind, Controlled Clinical Trial. PLoS One. 2016; 11(5):e0154195.

Smyth A, O'Donnell M, Lamelas P. et al. Physical Activity and Anger or Emotional Upset as Triggers of Acute Myocardial Infarction: Circulation. 2016; 134(15):1059-1067. 
Stubbs B, Koyanagi A, Hallgren M. et al. Physical activity and anxiety: A perspective from the World Health Survey. J Affect Disord. 2017; 208:545-552.

Subramanian SK, Sharma VK, Arunachalam V. et al. Effect of Structured and Unstructured Physical Activity Training on Cognitive Functions in Adolescents - A Randomized Control Trial. J Clin Diagn Res. 2015; 9(11):CC04-9.

Sun FK, Hung CM, Yao Y et al. The Effects of Muscle Relaxation and Therapeutic Walking on Depression, Suicidal Ideation, and Quality of Life in Breast Cancer Patients Receiving Chemotherapy. Cancer Nurs. 2016 Dec 5. [Epub ahead of print]

Tritter A, Fitzgeorge L, Prapavessis H. The effect of acute exercise on cigarette cravings while using a nicotine lozenge. Psychopharmacology (Berl). 2015; 232(14):2531-9.

Woodside H, Culos-Reed SN. Impact of yoga on quality of life for young adult noncurative cancer patients: A pilot study. J Clin Oncol. 2016; 34(3_suppl):249.

Yim J. Therapeutic Benefits of Laughter in Mental Health: A Theoretical Review. Tohoku J Exp Med. 2016;239(3):243-9.

Yuenyongchaiwat K. Effects of 10,000 steps a day on physical and mental health in overweight participants in a community setting: a preliminary study. Braz J Phys Ther. 2016; 20:367-373.

Zamani Sani SH, Fathirezaie Z, Brand S et al. Physical activity and self-esteem: testing direct and indirect relationships associated with psychological and physical mechanisms. Neuropsychiatr Dis Treat. 2016; 12:2617-2625.

Zhuang SM, An SH, Zhao Y. Yoga Effects on Mood and Quality of Life in Chinese Women Undergoing Heroin Detoxification: A Randomized Controlled Trial. Nurs Res. 2013; 62(4):260-8.

MUDr. Karel Nespor, CSc.

Psychiatric hospital Bohnice

drnespor@gmail.com

www.drnespor.eu

Received 05 Jan. 2017; Revised 08 Jan. 2017-10 Feb. 2017; Accepted 05 March 2017 